\title{
Inequalities in oral health among adolescents in Gangneung, South Korea
}

\author{
Se-Hwan Jung ${ }^{1}$, Myoung-Hee Kim² and Jae-In Ryu ${ }^{3^{*}}$ (D)
}

\begin{abstract}
Background: This study aims to evaluate inequality in oral health among adolescents and to explain the mechanisms of such inequalities in Gangneung, South Korea.

Methods: One thousand two hundred sixty-seven students in their first year from four vocational and three general schools participated in the baseline survey of 2011, and $84.7 \%$ of them were surveyed again in 2013. Oral examinations by the same dentist and a self-administered questionnaire were repeated during both waves. Outcome measure for oral health was the existence of untreated dental caries (DT). As socioeconomic position (SEP) indicators, school type (general vs. vocational), father's and mother's education, perceived economic status, and Family Affluence Scale (FAS) were measured. Variables measuring oral health related behaviours included tooth brushing frequency, frequency of eating snacks and drinking sodas, smoking, and annual visits to dental clinics. Chi-square tests and panel logistic regression were adopted to examine the associations between dental caries and SEP indicators by STATA version 15.1.
\end{abstract}

Results: Having a less educated father and attending a vocational school were significant predictors for untreated caries after controlling for SEP indicators. However, students from general schools, higher SEP by father's education, perceived economic status, or FAS, or having non-smoking experience or annual visits to dental clinics were more likely to stay caries-free.

Conclusions: There were socioeconomic inequalities in oral health on an adolescent panel. Given that oral health status during adolescents can persist throughout the course of a person's life, intervention to tackle such inequalities and school environments are required.

Keywords: Adolescent health, Schools, Socioeconomic factors

\section{Background}

Various studies have recognized that there are socioeconomic inequalities in health [1-3] and oral health $[4,5]$. A gap exists across all levels of socioeconomic groups, especially between the highest and the lowest ones. Furthermore, such inequalities are observed throughout the course of a person's life, from childhood to adulthood and into old age [6-9]. However, there are differing opinions for the existence of health inequality in a specific life stage: adolescence.

West $[10,11]$ suggested that adolescents exhibit dissimilar health inequality patterns when compared to other age groups because this group can be "characterised by the absence or disappearance of class variation." To the

\footnotetext{
* Correspondence: jaeinryu@khu.ac.kr

${ }^{3}$ Department of Preventive and Social Dentistry, College of Dentistry, Kyung Hee University, 26 Kyungheedae-ro, Dongdaemun-gu, Seoul 02447, South Korea Full list of author information is available at the end of the article
}

contrary, others have claimed that findings on health equality among adolescents are the result of inappropriate measurements for socioeconomic position (SEP) indicators $[12,13]$. These studies argued that commonly used SEP indicators, including education, occupation, and income levels, are not appropriate for adolescents. For example, there was a significant health gap in adolescents when using alternative SEP indicators such as the Family Affluence Scale (FAS) [14] and perceived socioeconomic status [15]. Subsequent to these debates, studies in different settings have attempted to verify both positions but a consensus stills has not been reached [16-18].

Recently, there have been several longitudinal studies dealing with inequality in adolescent oral health by SEP indicators. A life-course research in cohort of New Zealand children concluded that there was an effect from childhood SEP [19]. A study from Sweden showed

(c) The Author(s). 2018 Open Access This article is distributed under the terms of the Creative Commons Attribution 4.0 International License (http://creativecommons.org/licenses/by/4.0/), which permits unrestricted use, distribution, and 
that there is limited effect from SEP only after considering the previous experience of caries [20]. Polk et al. [21] and Newacheck [22] also reported that there was an SEP gradient in caries experiences in the U.S. Another longitudinal study from Iowa cohort revealed that there is a gap by SEP, especially maternal educational levels [23]. However, Curtis, using the same cohort data from Iowa Fluoride Study (IFS), recently argued that the role of SES in caries may not be as important as previously thought'. Meanwhile, another group of scholars have focused on school characteristics as an alternative to traditional SEP indicators [24-27] or influential effectors for behaviour, especially in S. Korea [28, 29], to determine health inequalities in adolescents. Others have reported that the residential area was a socioeconomic predictor of oral health inequality among adolescents [30, 31].

In terms of oral health, adolescence is of special importance because permanent dentition is complete and parental supervision of oral health behaviours weakens. Indeed, dental caries is a unique health condition aggravating during the schooling period. On the other hand, as they are amenable by health education and highly receptive to public health programs, interventions may be effective and the effects may be long lasting.

This study aims to evaluate inequality in oral health among adolescents by various SEP indicators and to explain the mechanisms of such inequalities in Gangneung, a city in South Korea.

\section{Methods}

\section{Study participants}

The aim of this panel study was to explore inequality in untreated caries among adolescents. The city of Gangneung has eleven high schools; two in rural areas and nine in urban areas [32]. By the school types, there were six general schools, four vocational schools, and one art school. The aim of the general schools is to support students' academic development and entry into college. By contrast, the aim of the vocational schools is to prepare students to enter the workforce directly after graduation. The one art school in this study was excluded due to its unique characteristics. First, the schools were categorized by its location as an urban or rural area. There was only one general and one vocational school in the rural area, so both of them were included. Among the other eight schools in the urban area, three vocational schools and two general schools were selected as study samples. Because they have fewer students than the general schools, all of the vocational schools were included. Two general schools were randomly selected by their close proximity to sampled vocational schools. Only first year students, 15-yr-old, were invited to participate in consideration of the follow-up survey after two years. All of the students were sixteen years old because middle school education is mandatory in South Korea, so the freshman in high school were all the same age. The research team sent the consent forms for oral examinations and surveys to students' parents or guardians with a brief introduction. Only students who returned completed consent forms from their parents or guardians were included in the study. Among 1371 students, ninety-seven declined to participate, and seven were excluded due to incomplete answers on the questionnaires. Finally, 1267 students were enrolled into the panel.

The Institutional Review Board in Gangneung-Wonju National University Dental Hospital reviewed and approved this study (GWNUDH IRB-2011-1-3). The Gangneung Health Centre and the Gangneung Office of Education with their district offices also consented to the study and supported the administrative process.

\section{Study variables and measurement}

Outcome measure for oral health was the untreated dental caries according to the Korean National Oral Health Survey (KNOHS) standard [33], which follows the guideline established by the WHO methods for oral health survey [34]. The untreated dental caries " $D$ " component, which includes carious teeth, filled teeth with recurrent decay, teeth with only the root left, defective filling with caries, temporary filling, and teeth with a filled tooth surfaces but with other surface decayed.

The examinations were conducted in a classroom of the surveyed schools using their table and chairs with a lightweight portable examination light. The plane mouth mirrors, periodontal probes that conform to WHO specifications, and several pairs of tweezers were supplied for the survey. The same dentist who was trained according to the Korean National Oral Health Survey (KNOHS) confirmed the students' oral status twice in three years. To have reliable intra-examiner reliability, the dentist examined 20 students before the main study. He reexamined them one week later for calibration, and the kappa consistency was 0.91, good agreement [35]. The status transition in dental caries between 2011 and 2013 were classified as follows: 1 ) no to no (remained cariesfree); 2) yes to no (received treatment); 3 ) no to yes (developed new dental caries); and 4) yes to yes (remained untreated caries).

Self-administered questionnaire surveys were administered, and items were derived from the Korean Youth Risk Behaviour Web-based Survey (KYRBWS) [36, 37] and from the guidelines in "Delivering better oral health: an evidence-based toolkit for prevention" [38]. As SEP indicators, school type (general vs. vocational), father's and mother's education level, perceived economic status, and FAS were measured. Father's and mother's education level was categorized into two groups; high school 
graduation or below vs. college graduation or above. The perceived economic status were re-categorised as high (high, high-middle, and middle) vs. low (middle-low and low). The FAS score was calculated by summing up dummy variables to represent the ownership of a family car, private bedroom for the student, computers, and the number of family vacations in the past year. FAS scores range from zero to nine, and students with scores larger than five were defined as 'high' and the others as 'low' group. Variable to measure oral health related behaviours included tooth brushing frequency ('twice or more a day' vs. 'less than twice a day'), frequency of snacks and drinking sodas ('less than once a day' vs. 'once or more a day'), smoking ('no' vs. 'yes'), and annual visits of dental clinics at least once a year ('yes' or 'no').

\section{Statistical analysis}

Annual prevalence of untreated caries (decayed teeth; 'D rate') and proportion of status transition in dental caries over the follow-up was examined according to various SEP indicators and oral health related behaviours by chisquare tests. In order to identify independent effects of SEP variables and contributions of covariates to oral health status with considering panel design, unconditional panel logistic regression models were estimated. Data analysis was carried out using STATA version 15.1 statistical software package (StataCorp, Texas).

\section{Results}

The characteristics of the study participants are displayed in the Table 1 . At the baseline survey of 2011, the participation rate was $92.4 \%$, and a total of 1267 students participated. The follow-up rate was $84.7 \%$ in 2013 with the drop of 194 students. Attrition was more common in vocational schools (27.3\%) than general schools (7.4\%). However, this did not present significant changes in the distribution of gender and SEP indicators of the sample between waves (Additional file 1: Table S1).

At both waves, the students who were from vocational schools, less educated fathers, and 'low' groups of perceived economic status and FAS were more likely to have untreated dental caries. As for oral health behaviours, tooth brushing and annual visits were inversely associated with D rates. Smoking was strongly associated with $\mathrm{D}$ rates in both waves (Table 2).

The odds ratios (ORs) for untreated caries were estimated after adjusting for SEP indicators only in Model 1 , and SEP indicators and oral health related behaviours covariates together in Model 2 (Table 3). As for D rates, fathers' education and school type remained significant after controlling for other SEP indicators. Even after incorporating health behaviour variables in the models, they still showed significant effects with attenuation.

The status transition in dental caries over the follow-up is shown in Table 4. Students from general schools, in higher SEP measured by father's education, perceived economic status, or FAS, drinking soda less than a day, without smoking experience, and to have annual visits to dental clinics were more likely to stay caries-free $(p<0.01)$.

\section{Discussion}

Our analysis of the adolescent panel in Gangneung, South Korea, verified the existence of significant differences in untreated dental caries by school type and father's education, and in caries experience by gender and father's education. Oral health-related behaviours attenuated but did not explain away such effects.

Differences in oral health by school type can be attributed to the fact that schools are a place where youths form a unique culture. Here, they begin to be independent from their family, spending most of the day with their peers. In a society where college graduation is the

Table 1 The characteristics of study participants by school type in Gangneung

\begin{tabular}{|c|c|c|c|c|c|c|}
\hline \multirow{2}{*}{$\begin{array}{l}\text { School } \\
\text { location }\end{array}$} & \multirow{2}{*}{$\begin{array}{l}\text { School } \\
\text { type }\end{array}$} & \multirow{2}{*}{$\begin{array}{l}\text { Sampled } \\
\text { population N }\end{array}$} & \multirow{2}{*}{$\begin{array}{l}\text { Respondents in } \\
\text { baseline } 2011 \\
\text { (1st grade, 15-yr-old) N }\end{array}$} & \multicolumn{2}{|l|}{ Gender } & \multirow{2}{*}{$\begin{array}{l}\text { Respondents in } \\
\text { follow-up } 2013 \\
\text { (3rd grade, 17-yr-old) N }\end{array}$} \\
\hline & & & & $\begin{array}{l}\text { Boys } \\
N(\%)\end{array}$ & $\begin{array}{l}\text { Girls } \\
N(\%)\end{array}$ & \\
\hline Total & & 1371 & 1267 & $690(54.5)$ & $577(45.5)$ & 1073 \\
\hline \multicolumn{7}{|l|}{ Rural } \\
\hline School A & General & 93 & 88 & $41(46.6)$ & $47(53.4)$ & 71 \\
\hline School B & Vocational & 155 & 133 & $48(36.1)$ & $85(63.9)$ & 99 \\
\hline \multicolumn{7}{|l|}{ Urban } \\
\hline School C & General & 341 & 335 & $335(100.0)$ & & 314 \\
\hline School D & General & 360 & 343 & & $343(100.0)$ & 324 \\
\hline School E & Vocational & 296 & 242 & $242(100.0)$ & & 168 \\
\hline School F & Vocational & 58 & 58 & $24(41.4)$ & $34(58.6)$ & 45 \\
\hline School G & Vocational & 68 & 68 & & $68(100.0)$ & 52 \\
\hline
\end{tabular}


Table 2 Numbers and percentages of adolescents who have untreated dental caries (D rate) by survey year in Gangneung

\begin{tabular}{lll}
\hline D rate & 201l (1st grade, & 2013 (3rd grade, \\
& 15 -yr-old) & $17-y r-o l d)$ \\
& $N=1267$ & $N=1073$ \\
\hline Total & $217(17.1)$ & $153(14.3)$
\end{tabular}

Gender

$\begin{array}{lll}\text { Girls } & 92(15.9) & 62(12.2) \\ \text { Boys } & 125(18.1) & 91(16.1)\end{array}$

School type

General

Vocational

$94(12.3)$

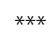

70(9.9)

$83(22.8)$

Father's education

College or above

$50(10.5) \quad * * * \quad 33(7.7)$

High school or below

137(19.8)

98(17.0)

Mother's education

College or above

46(13.3)

$31(10.3)$

High school or below

143(17.6)

101(14.4)

Perceived economic status

$\begin{array}{lllll}\text { High } & 145(15.6) & * & 99(12.6) & * * \\ \text { Low } & 72(21.4) & & 54(19.2) & \\ \text { FAS } & & & & \\ \text { High } & 171(15.6) & * * * & 115(12.5) & * * * \\ \text { Low } & 46(27.4) & & 38(26.0) & \end{array}$

Frequency of tooth-brushing

$\geq 2$

$<2$

$182(16.2)$

137(14.0)

16(17.4)

Frequency of eating snacks

$<1$

$\geq 1$

$71(15.7)$

$131(17.3)$

$118(13.4)$

35(18.9)

Frequency of drinking soda

$$
\begin{array}{ll}
<1 & 99(15.1) \\
\geq 1 & 95(18.6)
\end{array}
$$

134(13.6)

$19(21.1)$

\begin{tabular}{|c|c|c|c|}
\hline Yes & $84(14.6)$ & $55(10.7)$ & $* *$ \\
\hline No & 133(19.2) & $98(17.6)$ & \\
\hline
\end{tabular}

Smoking experience

$\begin{array}{llll}\text { No } & 124(13.8) & * * * & 91(12.0) \\ \text { Yes } & 93(25.3) & & 62(19.6)\end{array}$

Annual visits to dental clinic

${ }^{*} p<0.05,{ }^{* *} p<0.01,{ }^{* * *} p<0.001$

norm, vocational schools could be a symbolic representation of social disadvantages, which are related to poor health and undesirable health behaviours. There was a report that male and female students in Korean vocational schools are more likely to engage in nonconformant behaviours, including smoking, alcohol consumption, unexcused absences, running away from home, and sexual relationships, as well as to be involved

\begin{tabular}{|c|c|c|c|c|}
\hline D rate & Model $1 \dagger$ & & Model $2 \neq$ & \\
\hline \multicolumn{5}{|l|}{ Gender } \\
\hline Girls (vs. boys) & $0.65(0.39-1.06)$ & & $0.71(0.41-1.23)$ & \\
\hline \multicolumn{5}{|l|}{ School type } \\
\hline Vocational (vs. general) & $3.10(1.79-5.35)$ & $* * *$ & $2.68(1.46-4.92)$ & $* *$ \\
\hline \multicolumn{5}{|l|}{ Father's education } \\
\hline High school (vs. college) & $2.15(1.15-4.01)$ & * & $2.04(1.05-3.98)$ & $*$ \\
\hline \multicolumn{5}{|l|}{ Mother's education } \\
\hline High school (vs. college) & $0.92(0.48-1.76)$ & & $0.86(0.43-1.73)$ & \\
\hline \multicolumn{5}{|l|}{ Perceived economic status } \\
\hline Low (vs. high) & $1.03(0.62-1.71)$ & & $1.05(0.61-1.81)$ & \\
\hline \multicolumn{5}{|l|}{ FAS } \\
\hline Low (vs. high) & $1.82(0.95-3.49)$ & & $1.80(0.88-3.64)$ & \\
\hline \multicolumn{5}{|l|}{ Frequency of tooth-brushing } \\
\hline$<2$ (vs. $N \geq 2$ ) & & & $1.42(0.72-2.83)$ & \\
\hline \multicolumn{5}{|l|}{ Frequency of eating snacks } \\
\hline$\geq 1$ (vs. $N<1)$ & & & $1.64(1.00-2.70)$ & \\
\hline \multicolumn{5}{|l|}{ Frequency of drinking soda } \\
\hline$\geq 1$ (vs. $N<1$ ) & & & $1.13(0.66-1.95)$ & \\
\hline \multicolumn{5}{|l|}{ Smoking experience } \\
\hline Yes (vs. no) & & & $1.72(1.02-2.92)$ & $*$ \\
\hline \multicolumn{5}{|l|}{ Annual visits to dental clinic } \\
\hline No (vs. yes) & & & $1.91(1.22-3.01)$ & $* *$ \\
\hline
\end{tabular}

Table 3 Adjusted odds ratio and 95\% confidence intervals estimated from unconditional panel logistic regression models for D rate among adolescents in Gangneung ( $N=2003)$

† Model 1: adjusted for gender, school type, father's education, mother's education, subjective economic status, and FAS

₹ Model 2: adjusted for gender, school type, father's education, mother's education, subjective economic status, FAS, frequency of tooth brushing, eating snacks, and drinking soda, smoking, and annual visits to dental clinics ${ }^{*} p<0.05,{ }^{* *} p<0.01,{ }^{* * *} p<0.001$. - mean VIF $(=1.37)<10$

in assault, harassment, and adolescent prostitution [39]. Another Korean study found that even after controlling for individual-level SEP indicators and psychological stress, students in vocational schools engaged more in risky behaviours, for example smoking and drinking, and less in health-promoting behaviours, such as tooth brushing [40, 41].

There was no significant difference by gender in untreated dental caries. It is contrary to the findings in the 2012 Korean National Oral Health Survey, which showed higher prevalence of decayed teeth among girls by $10.6 \%$ [42]. Martinez-Mier and Zandona [43] argued that caries is multifactorial disease attributable to diverse factors, including genetic and hormonal factors as well as cultural influences, behavioural, and dietary practices. Kawamura and colleagues attributed the better oral health of girls to more frequent tooth brushing and their desires to possess healthy teeth [44]. It was suggested that their concern for good oral health motivates them 
Table 4 Condition transition for untreated caries over the two-year follow-up in Gangneung adolescent at 2013 ( $N=1073$ )

\begin{tabular}{|c|c|c|c|c|c|}
\hline & \multicolumn{4}{|c|}{ Caries status change (from 2011 to 2013) } & \\
\hline & $\overline{\mathrm{No}} \rightarrow \mathrm{No}^{\mathrm{a}}$ & $\mathrm{Yes} \rightarrow \mathrm{No}^{\mathrm{b}}$ & $\mathrm{No} \rightarrow \mathrm{Yes}^{\mathrm{c}}$ & Yes $\rightarrow$ Yes $^{d}$ & \\
\hline Total & $834(77.7)$ & $86(8.1)$ & $61(5.7)$ & $92(8.6)$ & \\
\hline \multicolumn{6}{|l|}{ Gender } \\
\hline Girls & $397(78.3)$ & $48(9.5)$ & $25(4.9)$ & $37(7.3)$ & \\
\hline Boys & $437(77.2)$ & $38(6.7)$ & $36(6.4)$ & $55(9.7)$ & \\
\hline School type & & & & & $* * *$ \\
\hline General & $585(82.5)$ & $54(7.6)$ & $37(5.2)$ & $33(4.7)$ & \\
\hline Vocational & $249(68.4)$ & $32(8.8)$ & $24(6.6)$ & $59(16.2)$ & \\
\hline Father's education & & & & & $* * *$ \\
\hline College or above & $361(84.5)$ & $33(7.7)$ & $23(5.4)$ & $10(2.3)$ & \\
\hline High school or below & $432(74.9)$ & $47(8.2)$ & $34(5.9)$ & $64(11.1)$ & \\
\hline \multicolumn{6}{|l|}{ Mother's education } \\
\hline College or above & $244(81.1)$ & $26(8.6)$ & $18(6.0)$ & $13(4.3)$ & \\
\hline High school or below & $545(77.8)$ & $55(7.9)$ & $38(5.4)$ & $63(9.0)$ & \\
\hline Perceived economic status & & & & & $* *$ \\
\hline High & $621(78.8)$ & $68(8.6)$ & $47(6.0)$ & $52(6.6)$ & \\
\hline Low & $209(74.4)$ & $18(6.4)$ & $14(5.0)$ & $40(14.2)$ & \\
\hline FAS & & & & & *** \\
\hline High & $732(79.2)$ & $77(8.3)$ & $52(5.6)$ & $63(6.8)$ & \\
\hline Low & $100(68.5)$ & $8(5.5)$ & $9(6.6)$ & $29(19.9)$ & \\
\hline \multicolumn{6}{|l|}{ Frequency of tooth-brushing } \\
\hline$\geq 2$ & $764(77.9)$ & $80(8.2)$ & $53(5.4)$ & $84(8.6)$ & \\
\hline$<2$ & $70(76.1)$ & $6(6.5)$ & $8(8.7)$ & $8(8.7)$ & \\
\hline \multicolumn{6}{|l|}{ Frequency of eating snacks } \\
\hline$<1$ & $699(79.1)$ & $67(7.6)$ & $47(5.3)$ & $71(8.0)$ & \\
\hline$\geq 1$ & $131(70.8)$ & $19(10.3)$ & $14(7.6)$ & $21(11.4)$ & \\
\hline Frequency of drinking soda & & & & & $* *$ \\
\hline$<1$ & $777(79.0)$ & $72(7.3)$ & $53(5.4)$ & $81(8.2)$ & \\
\hline$\geq 1$ & $57(63.3)$ & $14(15.6)$ & $8(8.9)$ & $11(12.2)$ & \\
\hline Smoking experience & & & & & *** \\
\hline No & $611(80.8)$ & $54(7.1)$ & $42(5.6)$ & $49(6.5)$ & \\
\hline Yes & $223(70.4)$ & $32(10.1)$ & $19(6.0)$ & $43(13.6)$ & \\
\hline Annual visits to dental clinic & & & & & ** \\
\hline Yes & $410(79.5)$ & $51(9.9)$ & $18(3.5)$ & $37(7.2)$ & \\
\hline No & $424(76.1)$ & $35(6.3)$ & $43(7.7)$ & $55(9.9)$ & \\
\hline
\end{tabular}

${ }^{\mathrm{a}} \mathrm{No} \rightarrow$ No as remaining caries-free, ${ }^{\mathrm{b}}$ Yes $\rightarrow$ No as being treated with fillings, ${ }^{\mathrm{c}}$ No $\rightarrow$ Yes as developing dental caries, and ${ }^{\mathrm{d}}$ Yes $\rightarrow$ Yes as remaining untreated caries ${ }^{* *} p<0.01,{ }^{* * *} p<0.001$

to visit dental clinics for treatment more often than males. Indeed, we found that students who visited dental clinics more regularly had a reduced likelihood of having untreated caries; adolescents who visited the dental clinic more regularly to receive treatment had less untreated caries.

It is noteworthy that father's education but not mother's education was a strong predictor of oral health in Korean adolescents. This is contrary to the report that mothers play an important role in the child development of oral health [45]. First, the cut-off level of mother's education might be inappropriate to capture the differences; in fact, only $30 \%$ of students in the panel had mothers who had graduated college, which means that the 'low' education group consisted of heterogeneous individuals, resulting in non-differential misclassification. 
Second, although parents' education level is associated with health literacy and awareness and thereby children's behaviours and service utilisation [46], parental influence wanes during transitional developmental periods [47]. Children have a desire to be similar with their friends, and such desires become stronger in older adolescents [48]. Therefore, mother's education might have little impact on the oral health and behaviours of adolescents in this panel. Along the same line, in our study, father's education as surrogate marker of household material conditions might be a better indicator of cultural and behavioural resources than mother's education. In Korea, fathers are generally family breadwinners, and there is a clear correlation between fathers' education and family economic status. As a mid-sized semiurban city, Gangneung provides less job opportunities. In this context, father's education could surpass other SEP indicators in representing household socioeconomic conditions.

The oral health behaviours of the study panel improved during the follow-up. For instance, the prevalence of eating less snacks went from under $37.5 \%$ at baseline to $82.7 \%$ at the second wave. Students exhibiting healthier behaviours increased dramatically in terms of oral health; they brushed teeth more and consumed less snacks and soda. All of this generally contributes to better oral health [49-51], and indeed D rates with untreated caries in our panel declined over time.

This study has some limitations. First, although differential sample attrition between general and vocational schools did not bring out differences in the distribution of socioeconomic factors among students, we cannot be sure that there was no systematic difference in oral health-related behaviours between participants and dropouts. Second, we could not fully explain why the strong effect of father's education persisted even after controlling for oral health-related behaviours. Third, because the panel was composed of high-school students only, it was hard to conduct follow-ups after their graduation. In order to examine long-term effects of oral health and related behaviours in adolescents, it would thus be necessary to expand the panel range to primary school students as they begin to formulate health behaviours.

\section{Conclusion}

We found socioeconomic inequalities in oral health based on an adolescent panel from Gangneung. Given that poor oral health and undesirable oral health-related behaviours during the adolescent period could last throughout a person's lifetime [52], there should be an immediate intervention to tackle such inequalities and school environments.

\section{Additional file}

Additional file 1: Table S1. The characteristics of the participants by sociodemographic information in Gangneung. (DOCX 14 kb)

\section{Acknowledgements}

This research was supported by Basic Science Research Program through the National Research Foundation of Korea (NRF) funded by the Ministry of Education (2011-0011208). The authors thank to the Gangneung Health Centre and the Gangneung Office of Education for supporting the administrative process.

\section{Availability of data and materials}

The datasets used and/or analysed during the current study are available from the corresponding author on reasonable request.

\section{Authors' contributions}

All authors contributed extensively to the work presented in this paper. SH has made substantial contributions to conception and design, acquisition of data, and interpretation of data; $J$ has been involved in analysis and interpretation of data and drafting the manuscript; $\mathrm{MH}$ has been revising it critically for important intellectual content; and All authors have given final approval of the version to be published. Each author have participated sufficiently in the work to take public responsibility for appropriate portions of the content and agreed to be accountable for all aspects of the work in ensuring that questions related to the accuracy or integrity of any part of the work are appropriately investigated and resolved.

\section{Ethics approval and consent to participate}

The research team sent the consent forms for oral examinations and surveys to students' parents/guardians with a brief introduction. Only students who returned completed consent forms from their parents/guardians were included in the study.

The Institutional Review Board in Gangneung-Wonju National University Dental Hospital reviewed and approved this study (GWNUDH IRB-2011-1-3).

\section{Competing interests}

The authors declare that they have no competing interests.

\section{Publisher's Note}

Springer Nature remains neutral with regard to jurisdictional claims in published maps and institutional affiliations.

\section{Author details}

${ }^{1}$ Department of Preventive Dentistry, College of Dentistry, Gangneung-Wonju University, 120 Gangneungdaehag-ro, Gangneung City, Gangwon Province 25457, South Korea. ${ }^{2}$ Center for Health Equity Research, People's Health Institute, 36 Sadangro 13-gil, 2nd floor, Dongjak-gu, Seoul 07004, South Korea. ${ }^{3}$ Department of Preventive and Social Dentistry, College of Dentistry, Kyung Hee University, 26 Kyungheedae-ro, Dongdaemun-gu, Seoul 02447, South Korea.

Received: 14 November 2017 Accepted: 17 April 2018

Published online: 24 April 2018

\section{References}

1. Townsend P, Davidson N. Inequalities in health: the black report. Harmondsworth: Penguin; 1982.

2. Whitehead M. The health divide: inequalities in health in the 1980s. London: Health Education Authority; 1987.

3. Marmot MG, Wilkinson RG. Social determinants of health. 2nd ed. Oxford; New York: Oxford University Press; 2006.

4. Marmot M, Bell R. Social determinants and dental health. Adv Dent Res. 2011:23(2):201-6.

5. Gilbert GH, Duncan RP, Shelton BJ. Social determinants of tooth loss. Health Serv Res. 2003;38(6 Pt 2):1843-62

6. Galobardes B, Lynch JW, Davey Smith G. Childhood socioeconomic circumstances and cause-specific mortality in adulthood: systematic review and interpretation. Epidemiol Rev. 2004;26:7-21. 
7. Ben-Shlomo Y, Kuh D. A life course approach to chronic disease epidemiology: conceptual models, empirical challenges and interdisciplinary perspectives. Int J Epidemiol. 2002;31(2):285-93.

8. Smith GD. Life-course approaches to inequalities in adult chronic disease risk. Proc Nutr Soc. 2007;66(2):216-36.

9. Smith GD, Hart C, Blane D, Hole D. Adverse socioeconomic conditions in childhood and cause specific adult mortality: prospective observational study. BMJ. 1998;316(7145):1631-5.

10. West $P$. Health inequalities in the early years: is there equalisation in youth? Soc Sci Med. 1997;44(6):833-58.

11. West $P$, Sweeting $H$. Evidence on equalisation in health in youth from the west of Scotland. Soc Sci Med. 2004;59(1):13-27.

12. Currie CE, Elton RA, Todd J, Platt S. Indicators of socioeconomic status for adolescents: the WHO health behaviour in school-aged children survey. Health Educ Res. 1997;12(3):385-97.

13. Piko BF, Fitzpatrick KM. Socioeconomic status, psychosocial health and health behaviours among Hungarian adolescents. Eur J Pub Health. 2007;17(4):353-60

14. Currie C, Molcho M, Boyce W, Holstein B, Torsheim T, Richter M. Researching health inequalities in adolescents: the development of the health behaviour in school-aged children (HBSC) family affluence scale. Soc Sci Med. 2008; 66(6):1429-36.

15. Goodman E, Adler NE, Kawachi I, Frazier AL, Huang B, Colditz GA. Adolescents' perceptions of social status: development and evaluation of a new indicator. Pediatrics. 2001;108(2):E31.

16. Goodman E. The role of socioeconomic status gradients in explaining differences in US adolescents' health. Am J Public Health. 1999;89(10):1522-8.

17. Siahpush M, Singh GK. A multivariate analysis of the association between social class of origin and current social class with self-rated general health and psychological health among 16-year-old Australians. Aust NZ J Med. 2000;30(6):653-9.

18. Vuille JC, Schenkel M. Social equalization in the health of youth. The role of the school. Eur J Pub Health. 2001;11(3):287-93.

19. Poulton R, Caspi A, Milne BJ, Thomson WM, Taylor A, Sears MR, Moffitt TE. Association between children's experience of socioeconomic disadvantage and adult health: a life-course study. Lancet. 2002;360(9346):1640-5.

20. Kallestal C, Wall S. Socio-economic effect on caries. Incidence data among Swedish 12-14-year-olds. Community Dent Oral Epidemiol. 2002;30(2):108-14.

21. Polk DE, Weyant RJ, Manz MC. Socioeconomic factors in adolescents' oral health: are they mediated by oral hygiene behaviors or preventive interventions? Community Dent Oral Epidemiol. 2010;38(1):1-9.

22. Newacheck PW, Hung YY, Park MJ, Brindis CD, Irwin CE Jr. Disparities in adolescent health and health care: does socioeconomic status matter? Health Serv Res. 2003;38(5):1235-52.

23. Warren JJ, Van Buren JM, Levy SM, Marshall TA, Cavanaugh JE, Curtis AM, Kolker JL, Weber-Gasparoni K. Dental caries clusters among adolescents. Community Dent Oral Epidemiol. 2017;45(6):538-44.

24. Fruhstorfer $\mathrm{BH}$, Mousoulis $\mathrm{C}$, Uthman $\mathrm{OA}$, Robertson W. Socio-economic status and overweight or obesity among school-age children in sub-Saharan Africa - a systematic review. Clin Obes. 2016;6(1):19-32.

25. Martins-Oliveira JG, Jorge KO, Ferreira RC, Ferreira EF, Vale MP, Zarzar PM. Risk of alcohol dependence: prevalence, related problems and socioeconomic factors. Cien Saude Colet. 2016;21(1):17-26.

26. Nabe-Nielsen $\mathrm{K}$, Krolner $\mathrm{R}$, Mortensen $\mathrm{LH}$, Jorgensen MB, Diderichsen $\mathrm{F}$. Health promotion in primary and secondary schools in Denmark: time trends and associations with schools' and students' characteristics. BMC Public Health. 2015;15:93.

27. Henkel D, Zemlin U. Social inequality and substance use and problematic gambling among adolescents and young adults: a review of epidemiological surveys in Germany. Curr Drug Abuse Rev. 2016;9(1):26-48.

28. Heo J, Oh J, Subramanian SV, Kawachi I. Household and school-level influences on smoking behavior among Korean adolescents: a multilevel analysis. PLoS One. 2014;9(6):e98683.

29. Kim H, Kim EK, Choi ES, Kim YJ, Lee HJ, Kim JJ, Jang HS, Shim KS, Jeon SN, Kang $\mathrm{YH}$, et al. The determinants of adolescent smoking by gender and type of school in Korea. J Prev Med Public Health. 2006;39(5):379-88.

30. Mathur MR, Tsakos G, Millett C, Arora M, Watt R. Socioeconomic inequalities in dental caries and their determinants in adolescents in New Delhi, India. BMJ Open. 2014;4(12):e006391.

31. Mathur MR, Tsakos G, Parmar P, Millett CJ, Watt RG. Socioeconomic inequalities and determinants of oral hygiene status among urban Indian adolescents. Community Dent Oral Epidemiol. 2016;44(3):248-54.
32. Gangneung City. The statistical yearbook of Gangneung city. Gangneung: Gangneung City; 2012

33. Ministry of Health and Welfare. Korean National Oral Health Survey 2010. Seoul: Ministry of Health and Welfare; 2010.

34. World Health Organization. Oral health surveys : basic methods. 5th ed. Geneva: World Health Organization; 2013.

35. Bowling A. Sample size and sampling for quantitative research. In: Research methods in health: investigating health and health services. 2nd ed. Buckingham; Philadelphia: Open University Press; 2002. p. 165-92.

36. Korea Centers for Disease Control and Prevention Reliability and validity of Korean youth risk behavior web-based survey questionnaire. Seoul: Korea centers for disease control and Prevention; 2009

37. Korea Centers for Disease Control and Prevention The statistics of Korean youth risk behavior web-based survey 2011. Seoul: Ministry of Education, Ministry of Health and Welfare, Korea centers for disease control and Prevention; 2012

38. Public Health England. Delivering better oral health: An evidence-based toolkit for prevention. 3rd ed. London: Department of Health, National Health Service, The British Association for the Study of Community Dentistry; 2014

39. Kim DS. Experience of parent-related negative life events, mental health and delinquent behavior among Korean adolescents. J Prev Med Public Health. 2007:40(3):218-26.

40. Jung SH, Tsakos G, Sheiham A, Ryu JI, Watt RG. Socio-economic status and oral health-related behaviours in Korean adolescents. Soc Sci Med. 2010; 70(11):1780-8.

41. Kim SI, Lee HR, Ma DS, Park DY, Jung SH. The differences of oral health-related behaviors by type of school among high school students in Gangneung city. J Korean Acad Oral Health. 2012:36(4):309-14.

42. Ministry of Health and Welfare. Ministry of Health and Welfare statistical year book 2012. Seoul: Ministry of Health and Welfare; 2012.

43. Martinez-Mier EA, Zandona AF. The impact of gender on caries prevalence and risk assessment. Dent Clin N Am. 2013;57(2):301-15.

44. Kawamura M, Takase N, Sasahara H, Okada M. Teenagers' oral health attitudes and behavior in Japan: comparison by sex and age group. J Oral Sci. 2008; 50(2):167-74.

45. Murakami K, Kondo N, Ohkubo T, Hashimoto $H$. The effect of fathers' and mothers' educational level on adult oral health in Japan. Community Dent Oral Epidemiol. 2016:44(3):283-91.

46. Mejia GC, Ha DH. Dental caries trends in Australian school children. Aust Dent J. 2011;56(2):227-30.

47. Hall-Scullin E, Goldthorpe J, Milsom K, Tickle M. A qualitative study of the views of adolescents on their caries risk and prevention behaviours. BMC oral health. 2015;15(1):141.

48. Stokes E, Ashcroft A, Platt MJ. Determining Liverpool adolescents' beliefs and attitudes in relation to oral health. Health education research. 2006; 21(2):192-205

49. Harris NO, García-Godoy F, Nathe CN. Primary preventive dentistry, 8th edn. Boston: Pearson; 2014

50. Daly B, Watt R, Batchelor P, Treasure E. Essential dental public health. Oxford; New York: Oxford University Press; 2002.

51. Pine CM. Community oral health. Oxford; Boston: Wright; 1997.

52. Due $P$, Krolner R, Rasmussen M, Andersen A, Trab Damsgaard M, Graham H, Holstein BE. Pathways and mechanisms in adolescence contribute to adult health inequalities. Scand J Public Health. 2011;39(6 Suppl):62-78.

\section{Ready to submit your research? Choose BMC and benefit from:}

- fast, convenient online submission

- thorough peer review by experienced researchers in your field

- rapid publication on acceptance

- support for research data, including large and complex data types

- gold Open Access which fosters wider collaboration and increased citations

- maximum visibility for your research: over $100 \mathrm{M}$ website views per year

At BMC, research is always in progress.

Learn more biomedcentral.com/submissions 